\title{
AUTONOMOUS VS. CONTROLLING EDUCATIONAL ENVIRONMENTS
}

\author{
Maja Matrić \\ Faculty of Education, University of Maribor, Slovenia \\ maja.matric@gmail.com
}

Professional Paper

doi:10.5937/jouproman7-19504

\begin{abstract}
Active and motivated students are much desired in the educational context. Learning how to lead the students to find intrinsic motivation for schoolwork, help them self-regulate their learning and feel autonomous in the learning process is an important task of every educator. In the article, we present autonomous and controlling educational environments in terms of motivation and regulation. We report of research which has examined the benefits of autonomy supportive learning and provide concrete guidelines teachers can adhere to in order to move away from controlling instruction, thus boosting the students perceived autonomy, self-regulation and motivation for schoolwork.
\end{abstract}

Key words: self-determination, autonomy, motivation, controlling instruction

\section{Introduction}

The basic assumption of self-determination theory (Deci \& Ryan, 2008) is that humans innately gravitate towards personal growth which is boosted or hindered by the environment. Self-determined individuals have the ability to show initiative and make autonomous decisions, and are motivated even when they are not inspired by genuine interest - as long as they can understand the value and the meaning of a task (Hui \& Tsang, 2012). In order to allow the individuals to fully exploit their abilities, stay motivated and feel well, the satisfaction of three basic psychological needs remains prerequisite, namely the need for competence, relatedness and autonomy (Stone, Deci, \& Ryan, 2008). The need for autonomy refers to allowing the individual a sense of choice, free will and self-determination (Stone, Deci, \& Ryan, 2009). More specifically, autonomy suggests active participation of individuals, who do not experience neither force or control from the environment, nor inner mechanisms which control their behaviour. Deci and Ryan (1987) explain autonomous actions as chosen and endorsed by the self. Such regulation through choice that stems from the individual is flexible and brings no pressure or the feeling that an action has to be done. As can be seen in Figure 1, different processes direct the individuals on their way to achieving goals. 

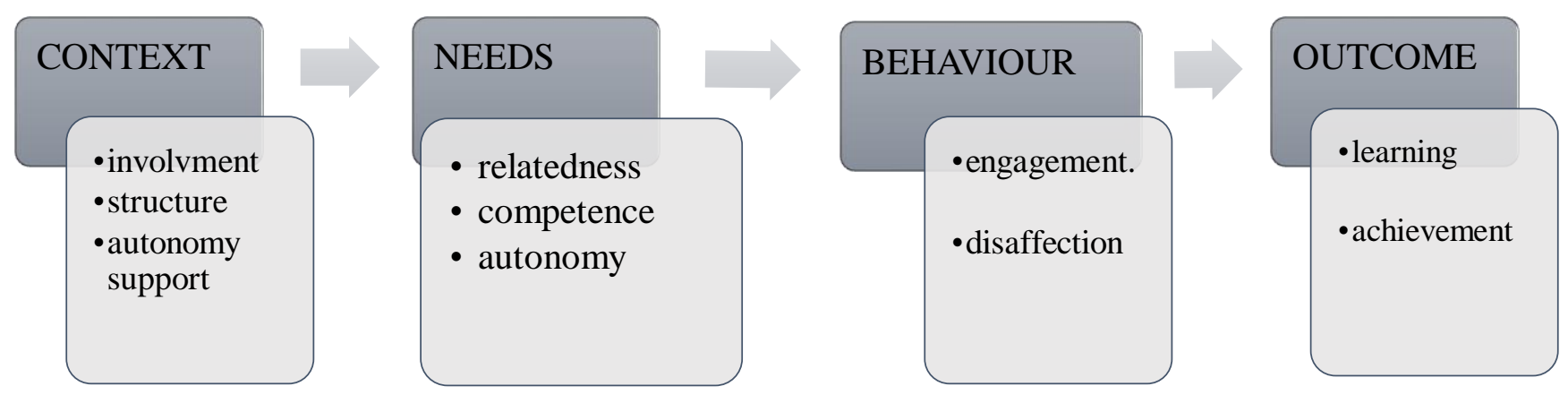

Figure 1. Model of relationships between the context, basic psychological needs, motivation and outcomes (adapted from Skinner, Furrer, Marchand, \& Kindermann, 2008)

The context, i.e. the school, has to enable involvement, and offer structure and autonomy support to the student. When these contextual conditions are satisfied, the individuals' needs for relatedness, competence and autonomy can be met (or not), which further directs the individuals' behaviour. Satisfied psychological needs will cause the student to be engaged, and the outcome of school participation will be better learning and achievements. On the other hand, not satisfying psychological needs will result in disaffected students, whose learning outcomes and achievements will be poor.

\section{Autonomy and control in the classroom}

Contexts can be described as autonomous or controlling, and according to this, individuals experience either autonomous or controlling motivation (Vansteenkiste, Lens, \& Deci, 2006). Deci and Ryan (1985; as cited in Ryan \& Deci, 2000) speak of motivation in cognitive evaluation theory and explain, that home and school can enable or hinder intrinsic motivation by helping individuals satisfy their needs for autonomy, relatedness and competence.
Authors continue to explain that the role of autonomy in this process is to help individuals identify with the task and find motivation for the task within themselves. In other words, the individual has to feel that his or her behaviour is self-determined. Such motivation results in better learning and more creativity, which are powerful aspects of education (Ryan \& Deci, 2000).

Deci and Ryan (2000) speak of two types of motivation: autonomous, where the motivation for performing a task comes from within; and controlled, where the motivation comes from the environment. Skinner, Wellborn and Connell (1990) explain that the students' perceptions of control significantly affect their engagement, therefore, the students will not perform at their best when they feel that they are forced to complete a task or that they are not autonomous enough. Niemiec and Ryan (2009) emphasize that we need intrinsic and extrinsic forms of motivation in schools, and see teacher autonomy support as key in helping students develop autonomous selfregulation. 
They suggest the following approaches, which the teachers should employ in order to help satisfy basic psychological needs:

(1) Use strategies which let the students chose learning activities, listen to their opinions and reduce pressure and control.

(2) Assess the students' achievement according to individual abilities of the students, give feedback and offer activities that are challenging for each student.

(3) Allow the students to feel connected to the teacher and the peers, reduce the experiences of rejectedness, which hinder the internalisation of external forms of motivation.

Reeve (2009) finds it paradoxical that even though the students perform and feel better in autonomy-supportive contexts, the teachers often resort to naturally occurring controlling instruction. The author describes controlling teachers as those who:

(1) perceive teaching from the teacher's standpoint only;

(2) interfere with their students' thoughts, feelings and actions; and

(3) direct students into a particular way of thinking, acting and feeling.

The author adds this should not be mixed with the teachers' suggestions about learning strategies, etc.; but is speaking of situations when the teachers explicitly pressure students into adopting the teachers' perspective, thus inducing environmentally controlled regulation, instead of enabling self-regulation within the students. Controlled regulation often forces the students to accomplish the tasks by means of reward, threats, deadlines, controlling speech, guilt or shame (Vansteenkiste, Lens, \& Deci, 2006), while Ryan and Deci (2000) add that external regulation decreases the students interest and effort in schoolwork, causing them to blame the teachers for their failure. Autonomy supportive learning environments will make the learning experience more pleasant (Chirkov, 2009), increase the students' motivation (Deci, Nezlek, \& Sheinman, 1981; Reeve, 2002), and contribute to the students' general well-being (Niemec \& Ryan, 2009; Guay, Ratelle, \& Chanal, 2008). Furthermore, teacher autonomy support predicts positive emotions and engagement in learning (Kaplan, 2018), increases experiences of self-determination and intrinsic learning motivation (Kiemer, Gröschner, Kunter, \& Seidel, 2018), elevates the sense of school belonging (Froiland, Davison, \& Worrell, 2016), and even reduces problematic online game use (Yu, Li, \& Zhang, 2015).

\section{Autonomous or controlling teacher}

In order to create opportunities for autonomy to occur, the teachers must accept the students' perspective, accept the way the students think, feel or act, as well as enable the students to be self-motivated and self-regulated (Reeve, 2009). Different authors suggest approaches which the teachers should use to help the learner satisfy the need for autonomy and we have chosen to present the paths of change by Stone, Deci and Ryan (2008) which we adapted for school setting, and autonomous instructional behaviours by Reeve (2009), which are summarized in Table 1. 
Table 1 Approaches which help boost teacher autonomy support

The paths of change (Stone, Deci, \& Ryan, 2008)

Asking open questions including inviting participation in solving important problems Active listening including acknowledging the employees' perspective

Offering choices within structure, including the clarification of responsibilities

Providing sincere, positive feedback that acknowledges initiative, and factual, nonjudgmental feedback about problems

Minimizing coercive controls such as rewards and comparisons with others

Stone, Ryan and Deci (2008) explain that asking open questions and inviting participation in solving important problems should be imbedded in supportive communication. The authors explain that open questions help students think and find a solution without implying what the preferred answers or solutions are (saying "What do you think?" instead of "Have you tried doing it by...?"). However, open questions will have no effect unless they are followed by active listening, where the teacher explicitly acknowledges the students idea or solution ("Let me see if I understand you correctly"). Such dialogue offers the student a range of possibilities to approach and complete the task in various logical ways. Once the task is completed, the teacher should offer a quality feedback which reflects the students' activity during the task. Therefore, simply praising the student for doing what the teacher told him to will not make the student feel more autonomous; in fact, such praise can appear controlling. The teacher should avoid using
Autonomous instructional behaviours (Reeve, 2009)

Nurturing inner motivational resources

Providing explanatory rationales

Using informational, noncontrolling language

Displaying patience to allow time for selfpaced learning to occur.

Acknowledging and accepting students' expressions of negative affect

rewards, as they have shown to lower intrinsic motivation (Vansteenkiste, Lens, \& Deci, 2006).

Reeve (2009) suggests more concrete teacher behaviours which can increase autonomy levels of the students. The author begins by explaining that the teacher has to nurture inner motivational resources, i.e. firstly understand what inner resources the student possesses, and then work on developing these resources. He continues by emphasizing the importance of providing explanatory rationales, which is particularly important in schools. Namely, the students are bound to find certain activities boring, pointless or uninteresting offering a rationale in these situations can still support autonomy and perhaps help the student realize why the activity is important. Next, the author suggests the use of noncontrolling language. Verbally pressuring the students to complete a task, hurrying them or pushing them in the direction of the desired right answer will prevent the student from using selfregulatory learning systems. 
Impatience should never be present on the part of the teacher. Instead, the teacher should allow time for the students to do the tasks at their own pace. Examples of impatience can be seen when the teacher simply tells the students the correct solution or completes the task instead of them, without giving them the chance to attempt solving the problem on their own. Finally, Reeve (2009) believes the teachers should make time to recognize the students' expressions of negative affect. Due to the nature of school, the teacher is bound encounter low motivation or behavioural problems among the students. The author explains that rules, requirements and demands of the school sometimes clash with the students' interests and inner desires, which may cause the students to complain and express a negative attitude towards schoolwork ("that's boring”, "you are asking us to do so much", etc.). The teachers should listen and by acknowledging, accepting and welcoming expressions of negative affect, demonstrate an understanding of the students' standpoint, their struggle and need for help. This negativity can be used in a constructive way to help students find motivation for classwork, or reset the task from something pointless (in the students' opinion) into something worth engaging in.

\section{Conclusions}

Self-determination theory framework emphasizes motivation as the driving force behind individuals' actions; particularly when they are driven by interest and genuine desire to discover and learn (Ryan \& Deci, 2000). Such operating conditions are optimal for successful completion of the task and will allow the individuals to fulfil their desire for autonomy, competence and relatedness (Stone, Deci, \& Ryan, 2008). Unfortunately, we cannot always remain intrinsically motivated and express innate interest in activities. This can be true of a student, who might perceive a particular subject or topic unnecessary; or an employee, who cannot understand the point of an early morning meeting. In such cases, we must rely on external motivation and the operational results of the task as the motivation for individuals' actions (Ryan \& Deci, 2000; Stone, Deci, \& Ryan, 2008). Even though external motivation might carry a negative connotation, Ryan and Deci (2000) explain that in autonomy and self-regulation supporting environments, external motivation can come close to intrinsic motivation in its nature. They emphasize that the power of external motivation should not be overlooked, but also should not be based on inappropriate forms of external regulation, such as rewards, deadlines, scolding, etc., as these actions undermine the individuals' motivation and act as an element of control (Lepper, Greene, \& Nisbett, 1973; as cited in Ryan \& Deci, 2000; Deci, 1971; as cited in Vansteenkiste, Lens, \& Deci, 2006; Stone, Deci, \& Ryan, 2008).

In order for quality external motivation to thrive, the students have to find themselves in autonomous school environments in the presence of autonomy-supportive teachers. Such teachers can successfully motivate the students for schoolwork (Hui \& Tsang, 2012), and recognize and foster the students' inner resources (Reeve, 2009). 


\section{Resources}

- Chirkov, V. I. (2009). A cross-cultural analysis of autonomy in education: A selfdetermination theory perspective. Theory and Research in Education, 7(2), 253-262. DOI: https://doi.org/10.1177/1477878509104330

- Deci, E. L., \& Ryan, R. M. (1987). The Support of Autonomy and the Control of Behavior. Journal of Personality and Social Psychology, 53(6), 1024-1037.

- Deci, E. L., \& Ryan, R. M. (2000). The »what « and »why« of goal pursuits: human needs in the self-determination of behaviour. Psychological Inquiry, 11(4), 227-268.

DOI: http://dx.doi.org/10.1207/S15327965PLI11 04_01

- Deci, E. L., \& Ryan, R. M. (2008). Selfdetermination theory: A macrotheory of human motivation, development, and health. Canadian Psychology/Psychologie Canadienne, 49(3), 182-185. DOI: http://dx.doi.org/10.1037/a0012801

- Deci, E. L., Nezlek, J., \& Sheinman, L. (1981). Characteristics of the rewarder and intrinsic motivation of the rewardee. Journal of Personality and Social Psychology, 40(1), 1-10. DOI: http://dx.doi.org/10.1037/0022-3514.40.1.1

- Froiland, J. M., Davison, M. L., \& Worrell, F. C. (2016). Aloha Teachers: Teacher Autonomy Support Promotes Native Hawaiian and Pacific Islander Students' Motivation, School Belonging, CourseTaking and Math Achievement. Social Psychology of Education: An International Journal, 19(4), $\quad$ 879-894. DOI: https://doi.org/10.1007/s1121

- Guay, F., Ratelle, C. F., \& Chanal, J. (2008). Optimal learning in optimal contexts: The role of self-determination in education.

Canadian

Psychology/Psychologie Canadienne, 49(3), 233-240. DOI: http://dx.doi.org/10.1037/a0012758

- Hui, F. K. P., \& Tsang, S. K. M. (2012). Self-Determination as a Psychological and Positive Youth Development Construct.
Scientific World Journal, 2012. DOI: http://dx.doi.org/10.1100/2012/759358.

- Kaplan, H. (2018). Teachers' Autonomy Support, Autonomy Suppression and Conditional Negative Regard as Predictors of Optimal Learning Experience among High-Achieving Bedouin Students. Social Psychology of Education: An International Journal, 21(1), 223-255. DOI: https://doi.org/10.1007/s1121

- $\quad$ Kiemer, K., Gröschner, A., Kunter, M., \& Seidel, T. (2018). Instructional and Motivational Classroom Discourse and Their Relationship with Teacher Autonomy and Competence Support--Findings from Teacher Professional Development. European Journal of Psychology of Education, 33(2), 377-402. DOI: https://doi.org/10.1016/j.tate.2016.03.005

- Niemec, C. P., Lynch, M. F., Vansteenkiste, M., Bernstein, J., Deci, E. L., \& Ryan, R. M. (2006). The antecedents and consequences of autonomous selfregulation for college: A self-determination theory perspective on socialization. Journal of Adolescence, 29(5), 761-755. DOI: http://dx.doi.org/10.1016/j.adolescence. 200 5.11 .009

- Niemiec, C. P., \& Ryan, R. M. (2009). Autonomy, competence, and relatedness in the classroom: Applying self-determination theory to educational practice. Theory and Research in Education, 7(2), 133-144. DOI:

https://doi.org/10.1177/1477878509104318

- Reeve, J. (2002). Self-determination theory applied to educational settings. In E. L. Deci \& R. M. Ryan (Eds.), Handbook of self-determination research (183-203). Rochester, NY: University Of Rochester Press.

- Reeve, J. (2009). Why Teachers Adopt a Controlling Motivating Style Toward Students and How They Can Become More Autonomy Supportive. Educational Psychologist, 44(3), 159-175. DOI: https://doi.org/10.1080/0046152090302899 0

- $\quad$ Ryan, R. M.; \& Deci, E.L. (2000). Intrinsic and Extrinsic Motivations: Classic 
definitions and new directions. Contemporary Educational Psychology, 25(1), 54-67. DOI: http://dx.doi.org/10.1006/ceps.1999.1020

- $\quad$ Skinner, E. A., Wellborn, J. G., \& Connell, J. P. (1990). What it takes to do well in school and whether I've got it: A Process model of perceived control in children's engagement and achievement in school. Journal of Educational Psychology, 82(1), 22-32.

DOI: http://dx.doi.org/10.1037/00220663.82.1.22

- $\quad$ Skinner, E., Furrer, C., Marchand, G., \& Kindermann, T. (2008). Engagement and disaffection in the classroom: Part of a larger motivational dynamic? Journal of Educational Psychology, 100(4), 765-781. DOI: http://dx.doi.org/10.1037/a0012840

- Stone, D. N., Deci, E. L., \& Ryan, R. M. (2008). Beyond Talk: Creating Autonomous Motivation through Self- determination Theory. Journal of General Management, 34(3), 75-91. DOI: https://doi.org/10.1177/0306307009034003 05

- $\quad$ Vansteenkiste, M., Lens, W., \& Deci, E. L. (2006). Intrinsic versus extrinsic goal contents in self-determination theory: Another look at the quality of academic motivation. Educational psychologist, 41(1), 19-31.

DOI: https://doi.org/10.1207/s15326985ep4101_ 4

- Yu, C., Li, X., \& Zhang, W. (2015). Predicting Adolescent Problematic Online Game Use from Teacher Autonomy Support, Basic Psychological Needs Satisfaction, and School Engagement: A 2Year Longitudinal Study. CyberPsychology, Behavior \& Social Networking, 18(4), 228-233. DOI: https://doi.org/10.1089/cyber.2014.0385 